\title{
Novas oportunidades para o espaço rural. \\ Análise exploratória no Centro de Portugal
}

\author{
Norberto Santos e Lúcio Cunha \\ Instituto de Estudos Geográficos \\ Universidade de Coimbra
}

A abordagem que pretendemos efectuar utiliza como espaço/suporte aquele a que normalmente associamos uma baixa intensividade da actividade humana, com uma relação directa com a paisagem menos moldada pela civilização urbano/industrial. Esta parte do mundo, que habitualmente denominamos por rural, é, multiforme nas suas características e, quando adequadamente intervencionada, de grande potencialidade endógena.

A população autóctone destes espaços, que associamos, ainda, a tempos do relógio menos espartilhantes do espaço de vida, quando a actividade económica é na integra assegurada pela actividade agrícola, tem, desde há muito, uma pluriactividade de grande significado no tempo e no espaço vividos, sendo "a expressão significativa das capacidades de adaptação de certos grupos sociais e situações locais precisas" (FROELICHER, 1982: 159, citado por LOURENÇO, 1991: 93). GASPAR refere, precisamente, que "os espaços rurais são, assim, cada vez menos os espaços de estabilidade - se é que alguma vez o foram" GASPAR (2004: 181). As últimas décadas têm debilitado os espaços rurais. Uma parte significativa das fragilidades e ameaças

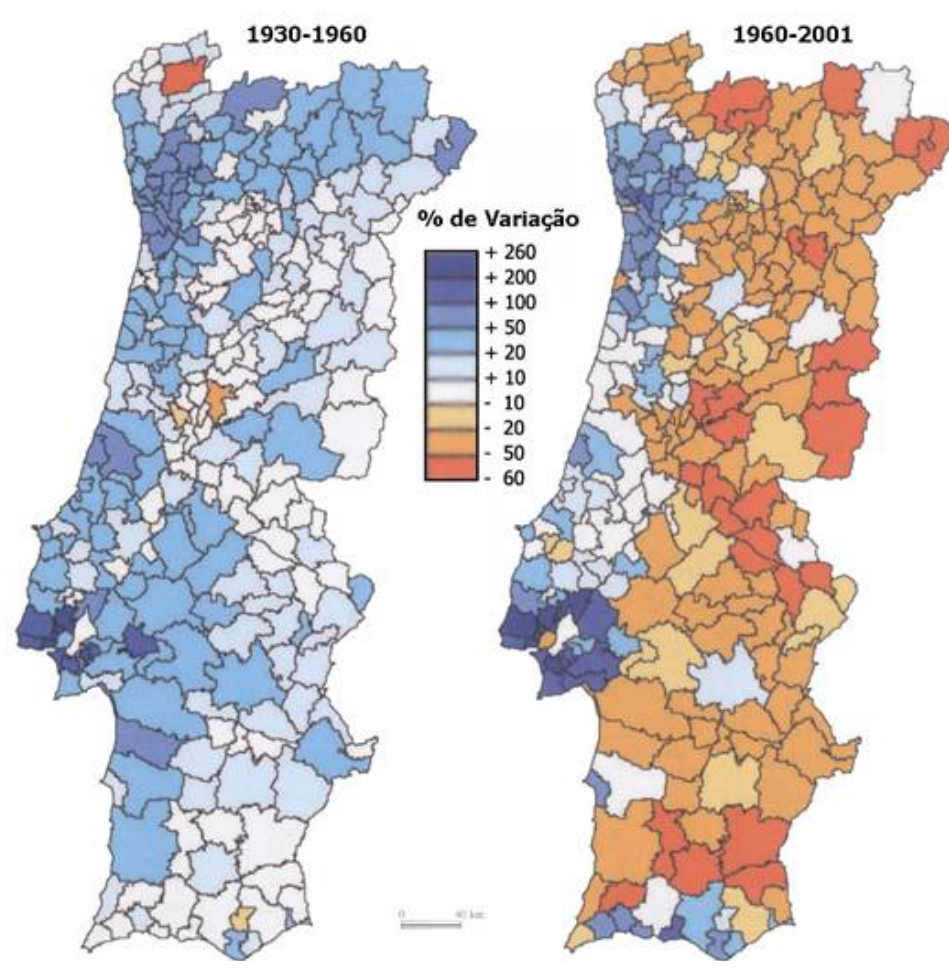

Figura 1 - Evolução da População: 1930-1960 e 1960-2001. Fonte: Geografia de Portugal com base em INE surgem por influência da acção desenvolvimentista explosiva do mundo urbano, que fez erodir os espaços envolventes, devido a relações paternalistas e modos de interacção de dependência do rural perante - urbano, que resultaram numa redução significativa das densidades demográficas (Figura 1) e numa falta de dinamismo económico, perante o não aproveitamento das oportunidades para valorização das suas próprias potencialidades.

O modelo territorialista de desenvolvimento é ou deve ser, hoje, assumido como 
fazendo parte de "redes, procurando assim superar a velha dicotomia entre modelos endógenos e exógenos" (CARDOSO, 2002: 28). Torna-se evidente que é necessário definir quais as funcionalidades que podem actuar de modo sustentável e exequível socioeconomicamente no espaço rural. A importância da agricultura é fulcral em todo o processo de estruturação rural, porque a agricultura não é só uma actividade económica, é também criadora das paisagens que nos atraem e constituem a forma de suporte organizacional deste mundo de menor intensividade económica e populacional. Numa visão inversa, "o abandono das actividades agrárias ou a diminuição da pressão antrópica nas paisagens culturais determina uma degradação deste recurso" (MOLTÓ MANTERO, 2004: 72), que é relevante evitar.

A globalização tem tido grande importância na valorização dos lugares a que associamos as identidades dos territórios, os saber-fazer específicos, os ex-líbris, as heranças patrimoniais e as tradições. Neste âmbito, o espaço rural ganha projecção, associado, na história recente, aos diferentes modos de Turismo em Espaço Rural, mas ampliada, hoje, à nova embalagem de actividades económicas existentes (termalismo), ao aproveitamento dos recursos hídricos para propósitos de lazer anteriormente apenas explorados em situação de beira-mar (barragens e praias fluviais), à nova cultura de relação Natureza/Ser Humano (roteiros, turismo cultural e de natureza), aos desportos (actividades equestres, golfe, desportos radicais). Como refere SIMÕES (1993 - Inforgeo) "o turismo tem sido considerado uma estratégia de desenvolvimento económico e social pelos mais variados argumentos, tais como o aumento de rendimentos, construção de novas infra-estruturas e formação de recursos humanos, criação de emprego e aumento da produção, entrada de divisas e, em geral, criação de mais riqueza" (SIMÕES, 1993). Os investimentos recentes, que têm levado para o mundo rural novas funcionalidades, são, precisamente, formas de corroborar o seu papel estratégico no desenvolvimento.

As questões da sustentabilidade do desenvolvimento e do nível de intervenção local são centrais para a abordagem que pretendemos efectuar. Importa, por isso, tomar em consideração a importância da conjugação das dimensões económica (eficiência, crescimento, estabilidade), social (equidade, solidariedade) e ecológica (reprodutibilidade dos recursos naturais), que MELA et al. (2001) sublinha, de forma a conseguir intervenções equilibradas e eficazes. Sabemos, também, que "a natureza e o ambiente deixam de ter a função de produção agro-silvo-pastoril prevalecente no passado, para adquirir uma representação estética, simbólica e lúdica pelos novos protagonistas urbano e institucionais" (CARDOSO, 2002: 35). Isto sucede porque a dinamização das cidades-região, com as suas áreas de influência (onde se inscreve o rural) é também, ou precisa de ser, um modo de desenvolvimento rural. Efectivamente, é pertinente sublinhar que, como refere CAVACO (2004):

“O desenvolvimento rural é essencialmente um problema de densidades de população (massa crítica de meios humanos), de actores e das suas relações, de iniciativas, institucionais e privadas, 
de capacidade organizativa; densidade de actividade económica, de capitais, de mão-de-obra qualificada, de saberes e de competências, de criação de emprego, de infra-estruturas, de serviços, de centros urbanos, como lembram Baptista (1999) e Cunha (2004: 258), para quem só existirá um mundo rural dinâmico se dispuser de uma estrutura urbana dinâmica e bem hierarquizada" (CAVACO, 2004: 100).

Ainda assim, é preciso ter em consideração que a relação entre urbano e rural é uma relação desigual. Os urbanitas criam o seu próprio meio rural, idílico e atractivo, depreciando os elementos que não correspondem ao seu estereótipo, resultado do desconhecimento das facetas que vão para além do isolamento, da tranquilidade e do bucolismo oferecidos pelo mundo rural (MALTÓ MANTERO, 2004).

Torna-se evidente que o rural é diverso, é multifuncional, é produtivo, é inovador, é competitivo e apresenta uma capacidade atractiva que potencia, numa relação de complementaridade, a do espaço urbano que o integra na sua área de influência.

O Fundo Europeu Agrícola de Desenvolvimento Rural (FEADER, 2007-2013) ajusta-se claramente ao propósito de promover os espaços rurais fora do âmbito das suas actividades tradicionais.

Como refere FERRÃO (2000), o mundo rural organiza-se em torno de uma tetralogia de aspectos: "uma função principal: a produção de alimentos; uma actividade económica dominante: a agricultura; um grupo social de referência: a família camponesa (...); um tipo de paisagem que reflecte a conquista de equilíbrios entre as características naturais e o tipo de actividades humanas desenvolvidas" (FERRÃO, 2000: 46). Todavia, as mudanças são evidentes e no mundo rural inscreve-se, também (ou começa a inscrever-se), a modernidade por oposição a espaços rurais profundos ou arcaicos, assentando esta dicotomia na proposição de novos elementos para o espaço rural: a mecanização e especialização na actividade agrícola, a dominância ou paridade de actividades não agrícolas, uma consciência urbana que assoma as famílias e a vontade de manter o equilíbrio entre Natureza e Ser Humano, no sentido da sustentabilidade.

O FEADER é proposto em 4 eixos: aumento da competitividade; melhoria do ambiente e da paisagem rural; qualidade de vida nas zonas rurais e diversificação da economia rural; abordagem LEADER (Ligações entre Acções de Desenvolvimento da Economia Rural). Entendendo os dois primeiros como fundamentais para a promoção da actividade agrícola, ajustamento às necessidades dos mercados e a propostas inovadoras de valorização das actividades ditas tradicionais, fundamentais para o mundo rural, interessam-nos mais, para este trabalho, as orientações presentes nos eixos 3 e 4.

Sabendo da importância dos Programas LEADER, parece importante manter uma política de valorização e ampliação dos investimentos efectuados assim como de promoção de novas propostas. 
O Eixo 3 do FEADER remete para um propósito que é central neste texto, $a$ qualidade de vida nas zonas rurais e diversificação da economia rural, assumida pelo agricultor, em situação de pluriactividade, através da constituição de microempresas.

Efectivamente, para o desenvolvimento local em espaços rurais é preciso uma efectiva participação das populações, no sentido de valorizar o processo de criação de uma consciência de cidadania, capaz de dar valor à conjugação entre a economia de mercado e a necessidade de conservação dos recursos. Para que isto suceda é fundamental que as políticas públicas estejam presentes, para promover investimentos, formações e apoio financeiro (CAMPANHOLA e SILVA, 2000).

Estes apoios de cima para baixo são, pois, fundamentais mas as determinações governamentais não são determinantes no processo, resultando, de facto, de uma construção social (CAVACO; 1996) de ambiente sistémico, porque "não se pode depender apenas da agricultura e ser exclusivamente agrícola, ignorando os níveis de urbanização, integração social e economia urbana" (RODRIGUES e CALLOU, www.eca.usp.br).

Assumindo que o processo deve contar com os diversos níveis de intervenção para que possa vingar, o FEADER apresenta um incentivo às actividades turísticas com centros de informação e a sinalização de locais turísticos; a valorização de infraestruturas recreativas, como as que oferecem acesso a zonas naturais e alojamentos com pequena capacidade, a par com o desenvolvimento e/ou a comercialização de serviços turísticos relacionados com o turismo rural.

Conjuntamente com estes investimentos surgem os associados aos serviços básicos para a economia e a população rurais, a conservação e valorização do património rural (natural e cultural).

Sabendo que o FEADER surge em íntima relação com o LEADER - que procura definir estratégias locais de desenvolvimento, obter parcerias locais dos sectores público e privado (denominados grupos de acção local), organizar grupos de acção local com poderes de decisão no que diz respeito à elaboração e execução de estratégias locais de desenvolvimento, promover a execução de abordagens inovadoras e projectos de cooperação - e reconhecendo o interesse autárquico e privado em promover localmente iniciativas e projectos no âmbito do turismo e do lazer, parecem criadas as condições para tornar o mundo rural num espaço de actividades de serviços, que valorizando o tempo livre das populações autóctones e alóctones, promova o desenvolvimento local.

\section{Potencialidades e investimentos (alguns exemplos)}

Um dos elementos que tem merecido alguma atenção, tanto por parte da oferta, como por parte da procura, é o termalismo. 

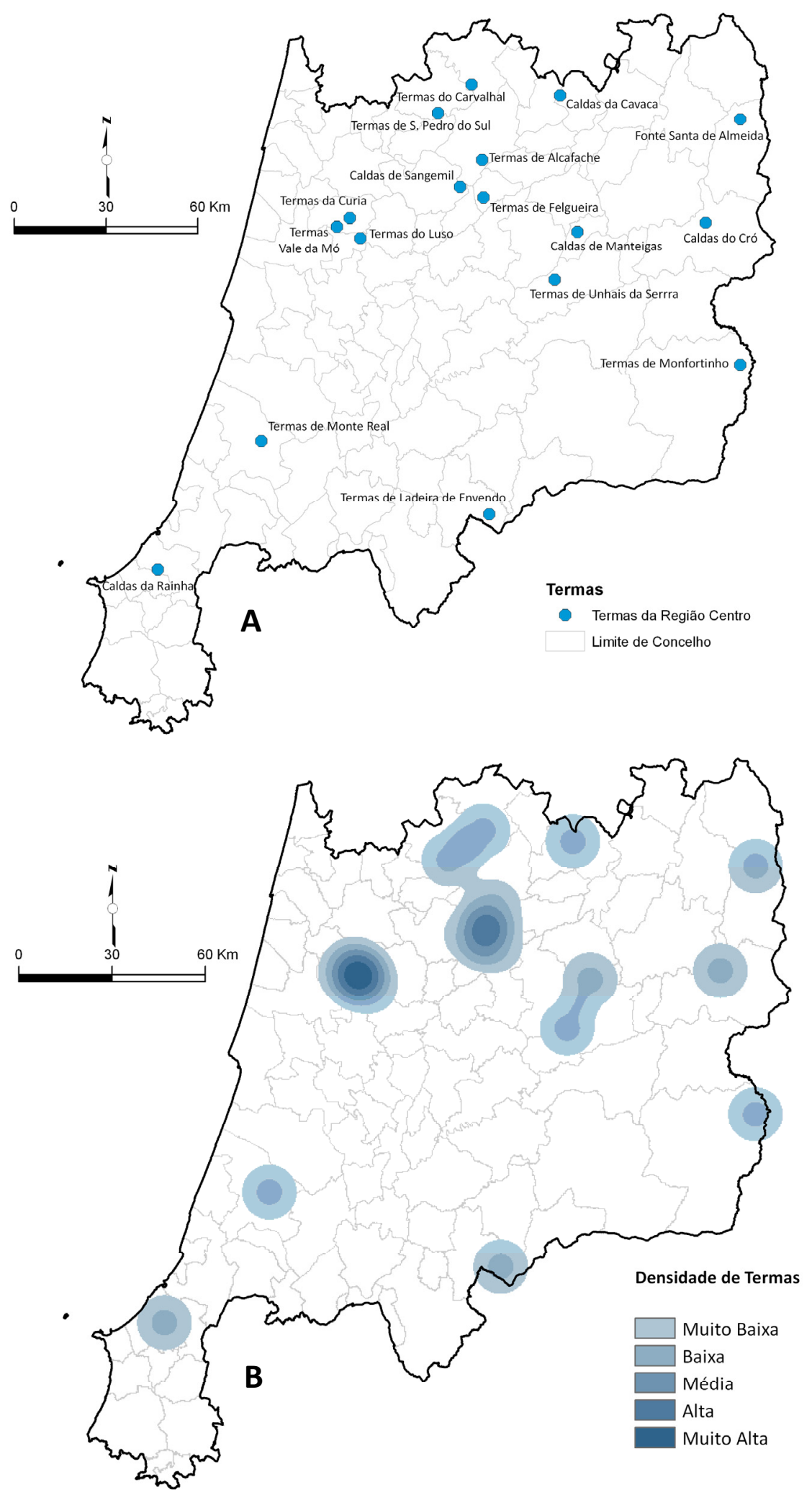

Figura 2 - Termas na Região Centro.

A: Distribuição de Termas e Caldas na Região Centro.

B: Análise da densidade de actividades de termalismo na Região Centro (Método Kernel). Fonte: Termas de Portugal. 
Perante a debilidade que atingiu o termalismo de saúde, devido à dificuldade em cativar clientela, o marketing das termas de lazer/saúde e os spas surgem como modo de revitalização de equipamentos subaproveitados, recuperação de antigas termas e caldas devolutas com edifícios de elevado valor patrimonial, valorização e diversificação dos serviços de outras e promoção da imagem de todas, através da difusão de novos propósitos. Estes, associados à ideia de saúde como requisito primeiro para a qualidade de vida, valorizam o aproveitamento dos tempos livres de estada nestes equipamentos em formas de lazer, quer de descanso, quer de desenvolvimento, quer de divertimento (sociabilidade). Os equipamentos que são responsáveis pela saúde, agora conjugadas com medicinas alternativas, são-o também para o lazer.

No caso da Região Centro, os lugares de promoção do turismo de lazer/saúde surgem no território em número significativo. Duas áreas evidenciam potencialidades acima da média na oferta destes equipamentos e serviços: Viseu (com as termas de Alcafache, da Felgueira e de S. Gemil, a sul; e as de S. Pedro, Carvalhal e Cavaca - em processo de recuperação - a norte) e Anadia/Mealhada (com as Termas do Luso, da Cúria e do Vale da Mó).

Outras existem, embora dispersas pela região, mas ainda assim muito importantes na oferta de serviços para uma população à procura de qualidade de vida através da valorização do lazer, da saúde e da descoberta de territórios de fuga ao bulício urbano, repletos de história e tradição e marcadamente identificados como guardiães últimos da natureza. É o caso de Monfortinho, Monte Real e Caldas da Rainha, cuja importância vai para além da influência regional e mesmo nacional e, ainda, as de Cró e Fonte Santa de Almeida, que com Monfortinho servem de bastiões deste tipos de serviços na raia central portuguesa. Também presentes estão as Termas da Ladeira de Envendos, em Mação, e na Serra da Estrela, as Caldas de Manteigas e as Termas de Unhais da Serra, em renovação e requalificação que motivarão, com certeza, uma clientela específica de espaços rurais à procura de qualidade, saúde e bem-estar. Outras há, como as da Amieira, em Soure, que continuam à espera de investimento que permita a recuperação do hotel, dos balneários e da casa das máquinas, assim como da vegetação exótica e autóctone que lhe está associada.

Um outro elemento fundamental são as praias fluviais. O turismo de sol e praia, normalmente associado ao turismo massificado, assim como à democratização dos lazeres, assume, hoje, novas formas menos massificadas e relacionadas com espaços com menores densidades relacionais, menos acessíveis e ainda com debilidades infraestruturais e de equipamentos consideráveis. Porém, através da intervenção do poder local (concelhos e freguesias), isoladamente ou em conjunto com investimentos privados, é possível valorizar as potencialidades de lazer de espaços ribeirinhos que conjugam paisagens e ludismo aquático de modos completamente diversos dos que temos à beira-mar. 

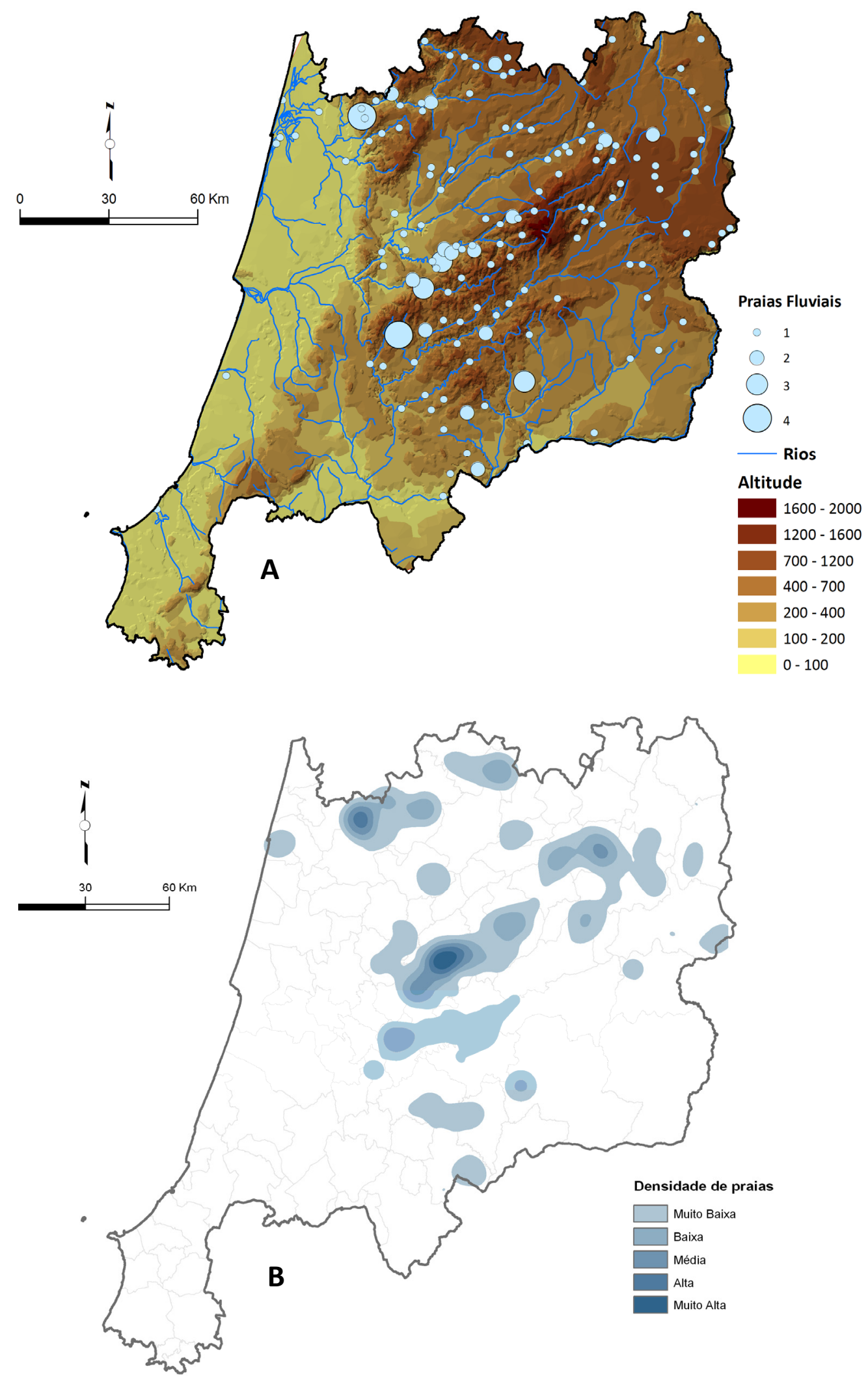

Figura 3 - Praias fluviais na Região Centro

A: Distribuição de Praias Fluviais na Região Centro.

B: Análise da densidade de lugares com praias fluviais na Região Centro (Método Kernel) Fonte: Atlas do Ambiente, Site Guia de Portugal. 
A oferta é muito diversa e a qualidade fica, quase sempre, aquém da desejada. As bandeiras azuis são poucas, a qualidade dos serviços não é a ideal, as acessibilidades são muitas vezes difíceis (embora este possa ser um elemento qualificativo dos lugares de lazer aquático fluvial). Verifica-se, contudo, um aumento e uma melhoria da oferta que importa ter em consideração porque a procura tem aumentado de forma significativa nos últimos anos: quer como forma de maior democratização das actividades de lazer, quer como modo alternativo de participação em actividades lúdicas.

No caso da Região Centro (Figura 3) a oferta é muito diversificada e explora precisamente territórios rurais, com debilidades ao nível da oferta de serviços em geral, e de serviços de lazer em especial, conjugando propostas de turismo natureza, com património e sociabilidade.

Na Figura 3A é possível verificar que a distribuição de praias fluviais, na Região Centro, acontece quase sempre no interior, a altitudes acima dos 400 metros e em núcleos identificáveis em torno de alguns rios onde parecem ter coalescido as condições físicas e a vontade das instituições e administrações. Neste sentido, salientam-se o rio Vouga, o rio

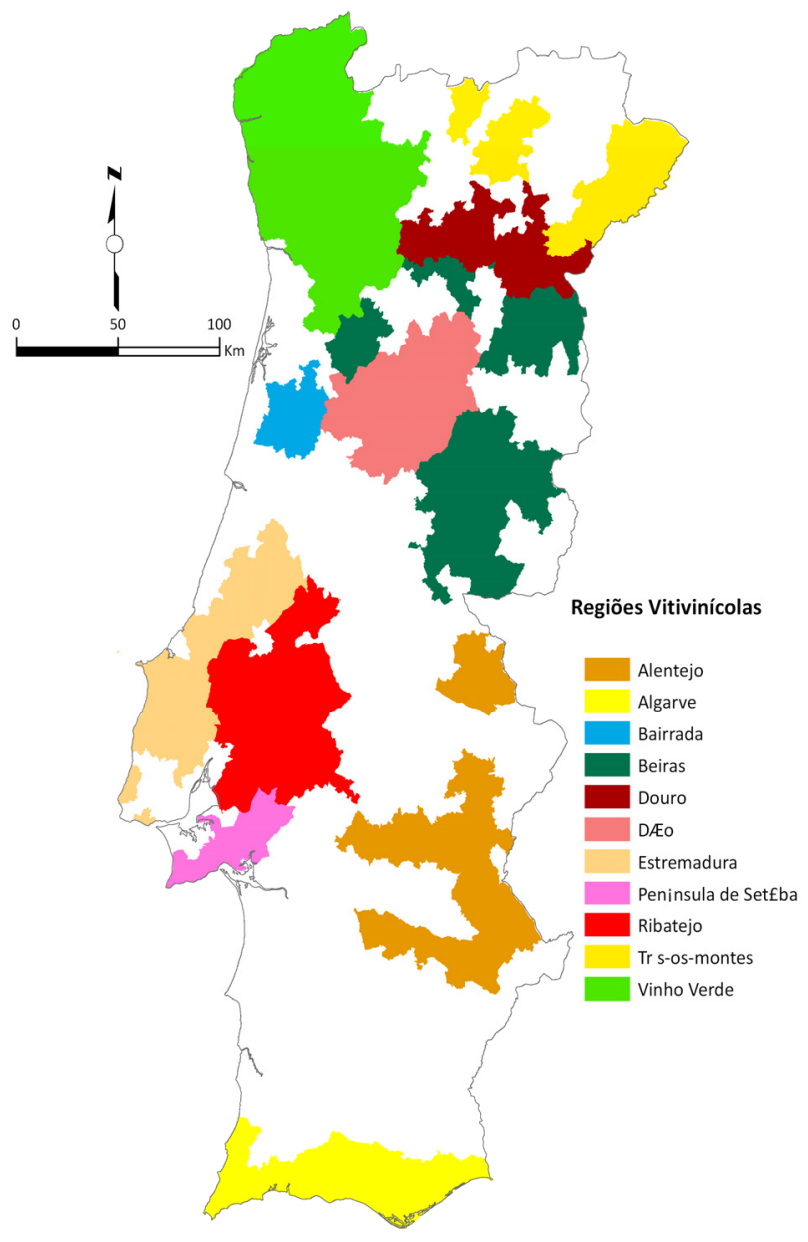

Figura 4 - Regiões Demarcadas (Portugal Continental) Fonte: Instituto do Vinho e da Vinha, Diários da República
Mondego e, particularmente, os seus afluentes Alva e Ceira, bem como o Rio Zêzere e alguns dos seus afluentes dando expressão à densidade de praias fluviais representada na Figura 3B.

Um terceiro elemento que escolhemos, para caracterizar as novas oportunidades de lazer nos espaços rurais, foi a produção vitivinícola. Sabemos que Portugal apresenta óptimas condições para a produção de vinho e que a qualidade do produto tem aumentado significativamente, devido à intervenção tanto de instituições reguladoras, como dos investidores privados, melhorando as vinhas, seleccionando as castas, ajustando os modos de produção. Com o território nacional praticamente coberto por Denominações de Origem ou por Indicações Geográficas, as Regiões Demarcadas (Figura 4) servem de 
referência à qualidade de um produto que pretende ser identitário em relação aos territórios onde é produzido, pela capacidade de promover a integração de produtos turísticos diversos em torno de propostas de grande pertinência para o desenvolvimento local sustentável. É incontornável a importância da Região Demarcada do Douro no contexto nacional e mesmo internacional, com grandes produções e grande qualidade. Todavia, a Região Centro integra um conjunto de Regiões que desde há muito se apresentam como referências vitivinícolas ou estão em desenvolvimento acelerado. No primeiro caso a Região do Dão é exemplar, a par com - Távora/Varosa, enquanto a Bairrada e os territórios da Bacia do Côa procuram integrar cada vez mais a qualidade, com a oferta de fileiras muito organizadas e assumidamente viradas para a promoção do produto vinho, desde o cultivo da vinha à venda directa, não apenas do vinho, mas da imagem de qualidade com associação de serviços ao território, através da vitivinicultura. Essa oferta, embora muito distribuída no território, surge relacionada com localizações específicas (Figura 5), em correlação directa com as quintas, as sociedades, as adegas, as caves dos produtores e engarrafadores (Figura 5A), que permite uma expressão densitária (Figura 5B) que permite identificar, de forma explicita, onde se localização as maiores potencialidades do produto vinho em Portugal. Até porque, é no rosário de lugares que se associam aos produtores/engarrafadores que vamos encontrar as melhores ofertas de enoturismo, marca clara de um investimento inovador ecológico e identitário que as próprias políticas nacionais procuram valorizar (Plano Estratégico Nacional para o Turismo). Assim, a leitura da Figura 5 ( $\mathrm{A} \mathrm{e} \mathrm{B)} \mathrm{mostra} \mathrm{que,} \mathrm{na} \mathrm{Região} \mathrm{Centro} \mathrm{o} \mathrm{core} \mathrm{do}$ sistema se encontra na Bairrada, onde a relação entre vinhos de mesa, espumantes e licores, conjuntamente com um conjunto de entidades reguladoras predominantes e investidores privados inovadores se revela de grande significado para a economia e a identidade territorial. Também importantes são os territórios do Dão e do Côa, assim como o Norte da Estremadura (Alcobaça, Terras de Aire, Lourinhã e Óbidos).

Outro elemento novo que tem estado a ser valorizado como produto de desenvolvimento local são as actividades equestres.

Sem grande projecção na Região Centro, o cavalo sempre teve maior impacto social e importância económica em terras ribatejanas e Área Metropolitana de Lisboa. Todavia, a reorganização administrativa da Região de Lisboa e Vale do Tejo veio oferecer à Região Centro mais um elemento de inovação que se tem difundido por vários lugares do território e que se apresenta imbuído das características ideias para singrar enquanto promotor de novas densidades relacionais e, por isso mesmo, de desenvolvimento local. A Figura 6 permite, precisamente, mostrar a importância do cavalo na Grande Lisboa e no Ribatejo, onde se concentra um número significativo dos centros hípicos portugueses, muito associados a situações de desporto equestre, mas também de lazer. 

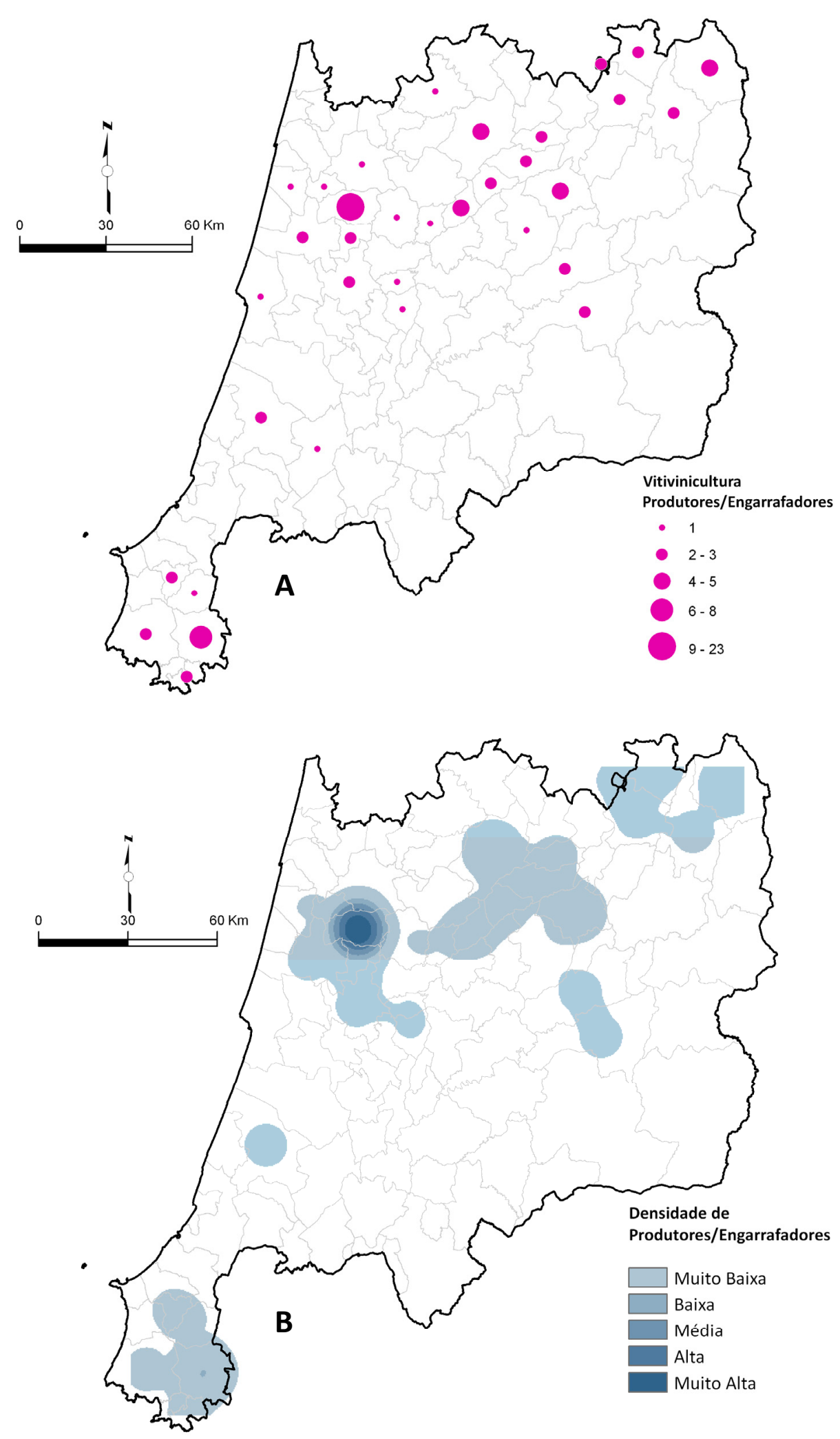

Figura 5 - Vitivinicultura na Região Centro

A: Distribuição de Produtores e Engarrafadores na Região Centro.

B: Análise da densidade Produtores e Engarrafadores na Região Centro (Método Kernel) Fonte: Atlas Fonte: http://www.vinhos.online.pt/. 


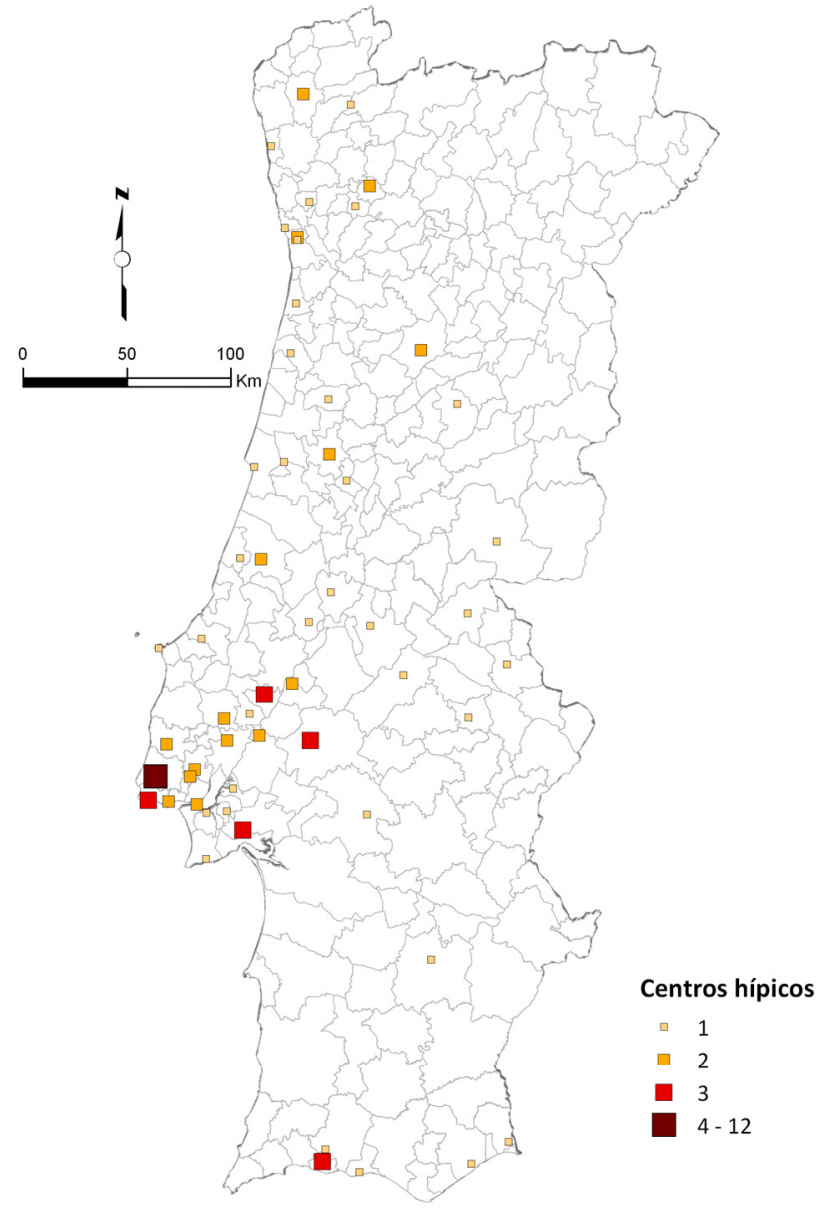

Figura 6 - Centros Hípicos em Portugal Continental. Fonte: Fonte: http://www.cavalonet.com/

Se bem que, do ponto de vista social, seja identificado com algum elitismo, devido aos custos que implica a manutenção e os equipamentos necessários para as actividades relacionadas com a equitação e o hipismo, as ofertas começam a ser diversificadas e acessíveis a bolsas de classes médias. Tornar possível a prática e o contacto com actividades equestres sem a necessidade de suportar as despesas de adquirir um cavalo e todas as despesas que Ihe estão associadas é uma forma de promover novas práticas de lazer. A oferta vai do contacto efémero e excepcional, passa por propostas de percursos equestres de tempos e espaços variados, e vai até aos serviços especializados de tratamento e serviços a cavalos cujos donos não têm nem tempo, nem espaço para oferecerem aos seus animais condições necessárias para o seu bem estar. Esta nova oferta de serviços consegue, na verdade, conjugar tanto o propósito do lazer do autóctone do lugar ou região, como a atracção que representa o contacto com um cavalo em percursos pensados para desfrutar a beleza paisagística e patrimonial dos lugares. Na Região Centro é possível encontrar já alguns lugares (Figura 7) onde essa oferta se torna realidade. Como é óbvio, o Oeste e o Médio Tejo apresentam uma concentração significativa de centros hípicos que funcionam como recursos para o território. Todavia, mais a norte começam a surgir investimentos pensados para serem atracção de clientelas específicas que procuram novas experiências ou serviços equestres qualificados. Torna-se evidente, pela análise da Figura 7 ( $\mathrm{A}$ e B) que é o litoral que apresenta uma oferta digna de registo e, no interior, a oferta equestre surge associada a concelhos com centros urbanos importantes na rede de cidades da região (Viseu, Castelo Branco, Seia), salientando uma distribuição em que a relação entre a capacidade de atracção urbana se conjuga com funcionalidades rurais, evidenciando a importância de existir uma relação de complementaridade e integração entre estes espaços, para que se possam potenciar, da melhor forma, as características endógenas dos territórios 

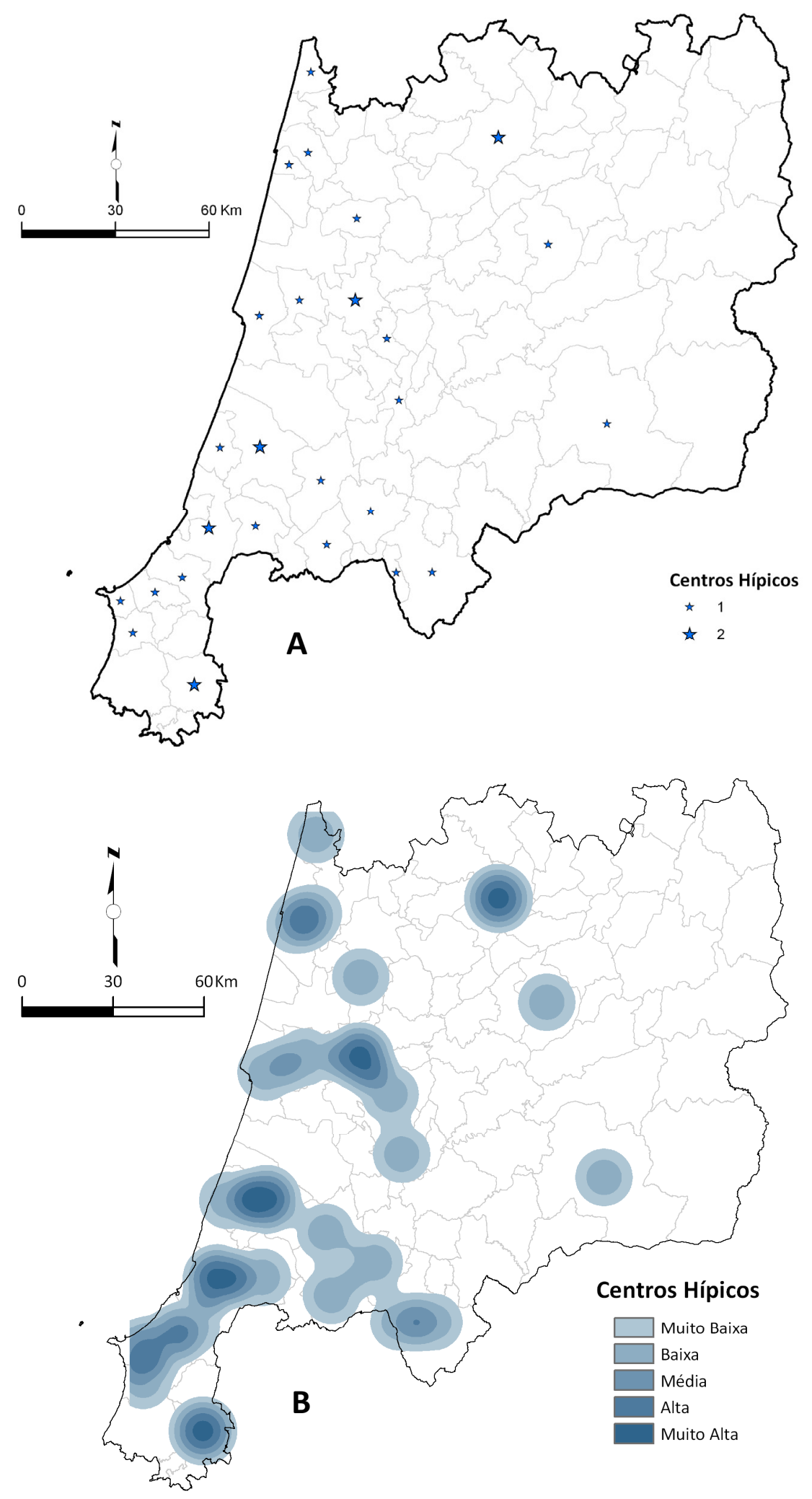

Figura 7 - Centros Hípicos na Região Centro de Portugal A: Distribuição dos Centros Hípicos na Região Centro de Portugal B: Densidade de Centros Hípicos na Região Centro de Portugal (Método Kernel) 
Finalmente podem ser considerados recursos para o desenvolvimento local de espaços rurais, os elementos ligados à Natureza, com particular relevância para aqueles que pelas suas características intrínsecas (raridade, espectacularidade, beleza) ou pelo significado sócio-cultural de que se revestem (interesse científico ou didáctico, simbolismo espiritual ou religioso, significado em termos de lazer ou desporto), facilmente podem ser integrados em políticas regionais ou locais de desenvolvimento territorial.

Estão neste caso as árvores notáveis (Figura 8), referenciadas pela DirecçãoGeral de Recursos Florestais e disponibilizadas através do Atlas do Ambiente Digital, muitas delas autênticos monumentos à vida vegetal, de inegável interesse pedagógicodiidáctico. Tratando-se de árvores que, pelo seu porte, idade, raridade ou ainda por motivos históricos e culturais se distinguem de outros exemplares (PINHO, s/d), correspondem tanto a carvalhos, sobreiros, castanheiros, testemunhos raros dos povoamentos autóctones da região, como a pinheiros ou eucaliptos, e mesmo árvores de fruto ou a espécimes decorativas, que à escala da Região Centro se distribuem de forma mais ou menos homogénea. Ainda que neste conjunto estejam espécimes com importância científica, cultural e pedagógico-cultural diversas, muitas destes exemplares são hoje, a nível municipal, autênticos ícones, perfeitamente integrados nas estratégias de desenvolvimento local.

Porventura mais importantes, sobretudo em tempos de forte valorização dos exotismos paisagísticos encontrados no mundo rural, são os elementos do património geomorfológico (Figura 9), que pelas suas características de relevância científica, espectacularidade ou raridade possam ser apelidados como "monumentos" (CARVALHO, 1999). Dos elementos da geodiversidade (GRAY, 2004), cuja relevância estética ou simbólica justifica, por um lado, a integração em estratégias de desenvolvimento e, por outro, a adopção de medidas de conservação e valorização, destacam-se, em particular, alguns elementos geomorfológicos situados, quer em espaços montanhosos, quer no litoral, ligados à dinâmica da linha de costa. Nos espaços montanhosos destacam-se elementos ligados à paisagem granítica das Serras do Montemuro, Freita e Caramulo, à paisagem cársica dos Maciços de Sicó e Estremenho e à paisagem glaciar herdada patente no Maciço Central da Serra da Estrela. Na linha de costa da região merecem referência alguns elementos ou sistemas geomorfológicos ligados à evolução de costas baixas e arenosas (Laguna de Aveiro, por exemplo) e de costas com arribas Rochosas (como por exemplo o Cabo Carvoeiro). No conjunto, define-se um padrão regional que, claramente, pende para o interior montanhoso, o que vem ao encontro daquilo que é a rede de áreas protegidas e Natura 2000 da região. 

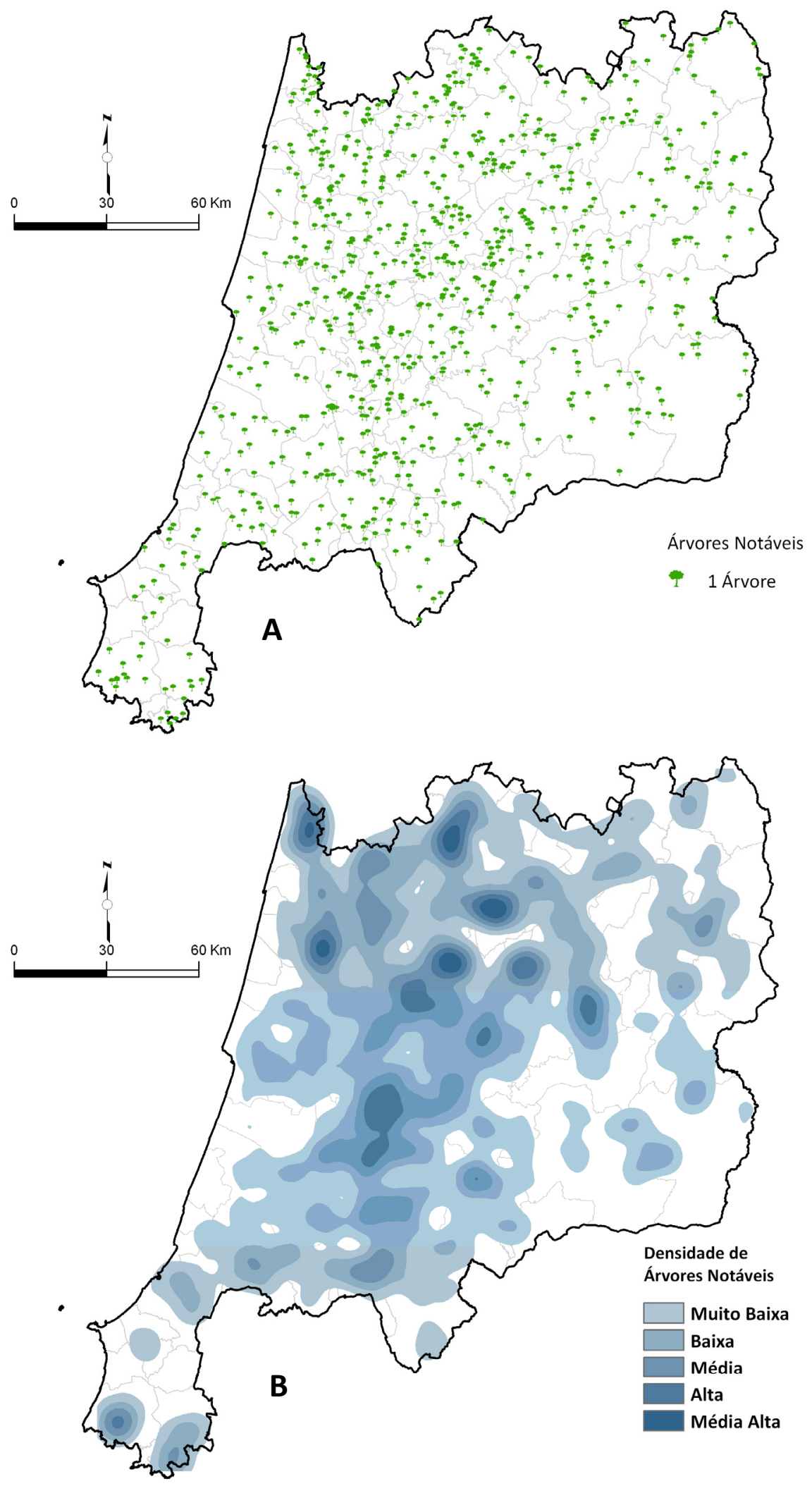

Figura 8 - Árvores notáveis na Região Centro de Portugal A: Distribuição das Árvores Notáveis na Região Centro B: Densidade das Árvores Notáveis na Região Centro (Método Kernel) Fonte: Atlas do Ambiente. 

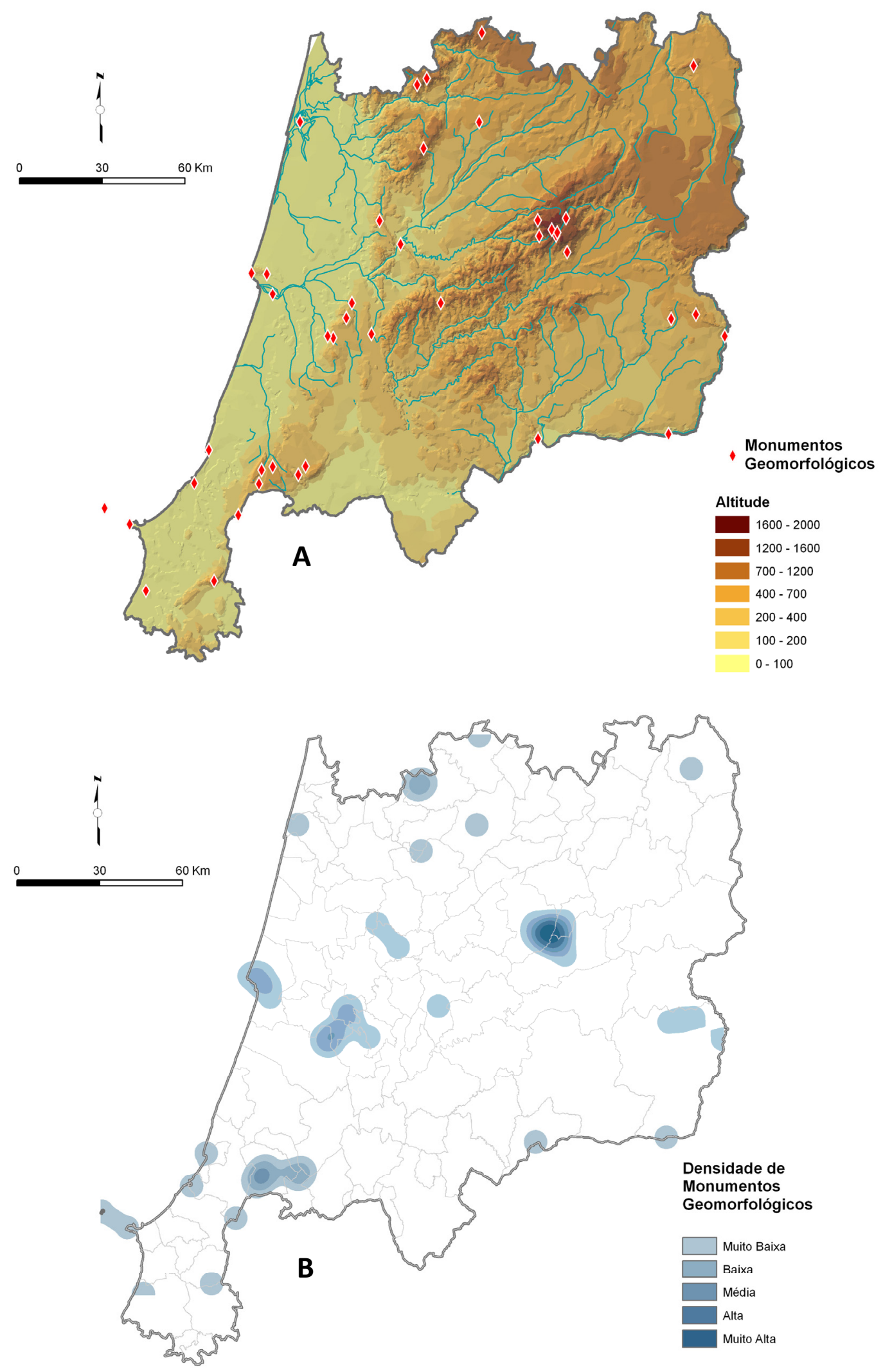

Figura 9 - Monumentos Geomórfológicos na Região Centro de Portugal A: Distribuição de Monumentos Geomorfológicos na Região Centro B: Densidade de Monumentos Geomorfológicos na Região Centro (Método Kernel) Fonte: Elaboração Própria 

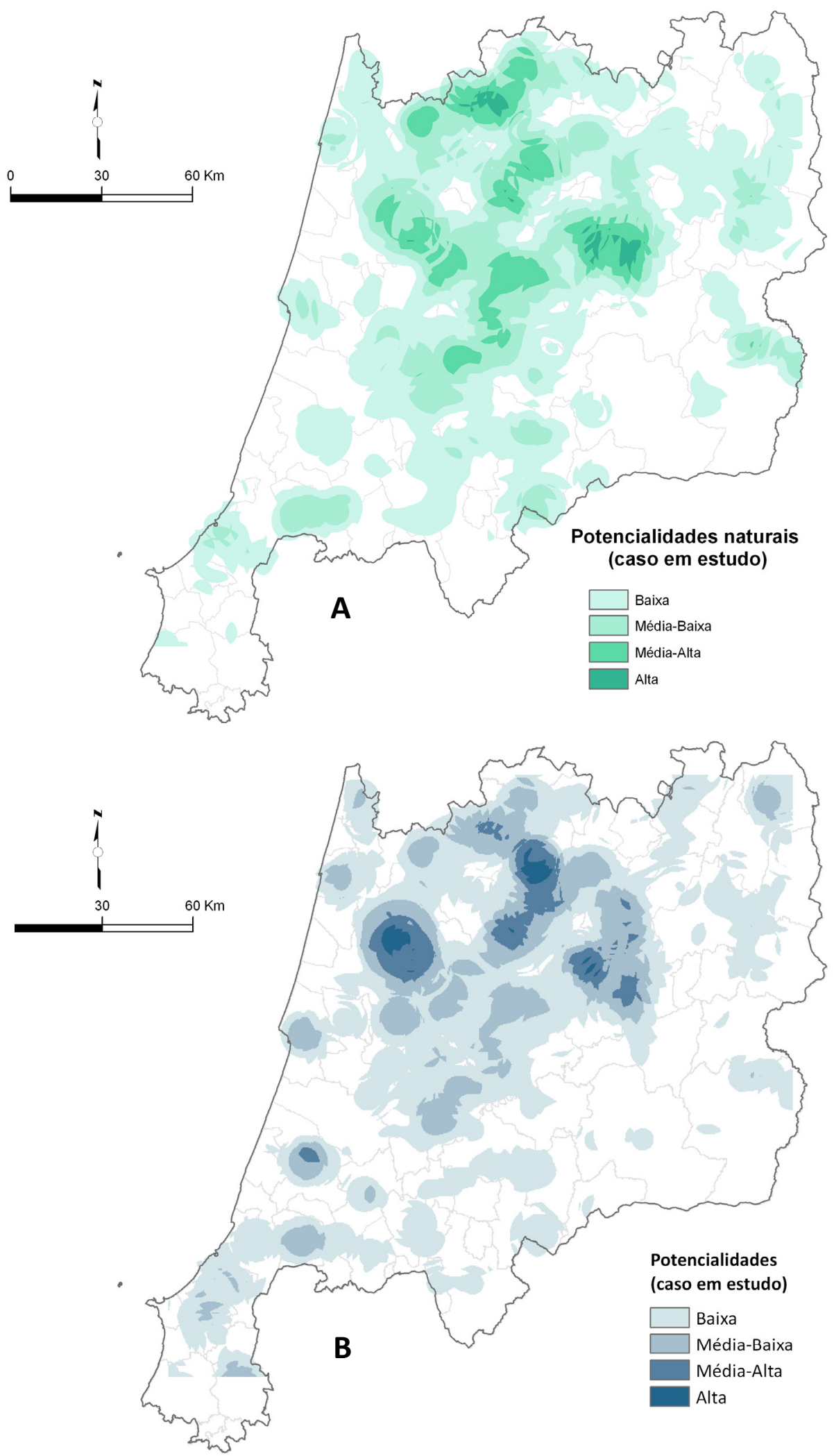

Figura 10 - Carta Síntese das Potencialidades Patrimoniais seleccionadas (Região Centro) A: Potencialidades Naturais; B: Total das Potencialidades seleccionadas Fonte: Elaboração Própria 
Este facto não é de estranhar, uma vez que, apesar de, em regra, serem indicados argumentos de natureza biótica ou ecológica para a classificação e delimitação de áreas protegidas, a influência que os elementos geomorfológicos detêm na construção da paisagem e como suporte ecossistémico é, de facto, o factor base da classificação (CUNHA, 2006), porque suporte de todos os outros. Servem como exemplos os Parques Naturais da Serra da Estrela, das Serras de Aires e Candeeiros ou do Tejo Internacional e do Douro Internacional, bem como os sítios da Rede Natura da Serra do Montemuro ou da Serra de Sicó. Até aos anos (19)80 a classificação de um território como área ambientalmente protegida era tida, essencialmente, como factor de constrangimento ao desenvolvimento local pelas limitações que impunha em termos das actividades económicas (agricultura, pecuária, indústria extractiva, turismo). Hoje, este estatuto, pelo valor simbólico que acrescenta aos territórios e pela capacidade de atracção de visitantes que promove, é um importante factor de marketing territorial à escala local e regional (SEXTO, 2006), indispensável-à prossecução de políticas de desenvolvimento.

\section{Conclusão}

São muitos os elementos patrimoniais naturais, culturais e económicos do mundo rural português que podem constituir factores de desenvolvimento. São também já muitas as actividades de lazer e desportivas que, utilizando estes recursos patrimoniais, aos poucos começam a animar os espaços de baixa densidade económica, infra-estrutural e demográfica. Por outro lado, um pouco por todo o mundo rural despontam ou ressurgem novas pólos de lazer utilizando quer recursos naturais (praias fluviais; termas), quer actividades rurais mais ou menos tradicionais (enoturismo; actividades equestres, entre outros).

A lista atrás apresentada não é necessariamente exaustiva no que diz respeito aos recursos nem no que se refere às possibilidades de desenvolvimento local. No entanto, permite já uma imagem de conjunto da região e das suas potencialidades territoriais através de novas formas de desenvolvimento local. Utilizando as possibilidades técnicas do software SIG utilizado foram construídos dois mapas, um que traduz o somatório das potencialidades naturais e um outro que traduz o somatório do conjunto de potencialidades elencadas ao longo deste texto. Esta lógica de associação ou de somatório de potencialidades reflecte também as lógicas de complementaridade entre a fruição de diferentes recursos, capaz de permitir a criação de imagens ou mesmo produtos turísticos e de lazer característicos do espaço rural.

Numa análise breve do conjunto regional distinguem-se algumas regiões montanhosas representativas sobretudo das potencialidades naturais (caso da Serra da Estrela) e áreas menos montanhosas como as regiões de Dão-Lafões ou do Baixo Vouga em que as potencialidades termais são complementadas pelas praias fluviais, 
pelo enoturismo e por elementos naturais mais ou menos próximos. Qualidade, quantidade, diversidade e complementaridade serão, assim, palavras-chave no quadro de desenvolvimento futuro do mundo rural do Centro de Portugal.

Ao ver reabilitada a sua diversidade e reajustadas à contemporaneidade as acessibilidades, a qualidade de vida potencial e o seu papel de "preservatório" natural e cultural, o mundo rural assume-se como um continuum de desenvolvimento urbanorural, de importância central no processo de conjugação da sustentabilidade com os interesses económicos.

Bibliografia

CARVALHO, A. M. Galopim (1999) - Geomonumentos. Lisboa, 30 p.

CAVACO, Carminda (2005) - Diferenciação regional da função turística. In MEDEIROS, Carlos Alberto (Dir.) Geografia de Portugal, Parte XI, CAVACO, Carminda, O Turismo e as Novas Dinâmicas territoriais, Circulo de Leitores, Rio de Mouro, p 385-399.

CAVACO, Carminda (2005) - Os espaços de turismo. In MEDEIROS, Carlos Alberto (Dir.) Geografia de Portugal, Parte XI, CAVACO, Carminda, O Turismo e as Novas Dinâmicas territoriais, Circulo de Leitores, Rio de Mouro, p 408-422.

CAVACO, Carminda (2005) - Turismo e desenvolvimento regional e local. In MEDEIROS, Carlos Alberto (Dir.) Geografia de Portugal, Parte XI, CAVACO, Carminda, O Turismo e as Novas Dinâmicas territoriais, Circulo de Leitores, Rio de Mouro, p 400-407.

CAVACO, Carminda, (1996) - Turismo e desenvolvimento local. In RODRIGUES, Adyr (Org.) Turismo e Geografia: reflexões teóricas e enfoques regionais. Hucitec, São Paulo, p 94-121.

CHAMPANHOLA, Clayton e SILVA, J. Graziano (2000) - Directrizes de políticas públicas para o novo rural brasileiro: incorporando a noção de desenvolvimento local. In CHAMPANHOLA, Clayton e SILVA, J. Graziano (Org.), O novo mundo rural: políticas públicas, Embrapa, S. Paulo, p. 61-91.

CUNHA, Lúcio (2006) - “Para quê e a quem serve a Geomorfologia”. Aurora, Braga, 0, pp. 27-40.

FERRÃO, João (2000) - Relações entre mundo rural e mundo urbano. Evolução histórica, situação actual e pistas para o futuro. In Sociologia, Problemas e Práticas, 33, CIES, Celta, Oeiras, pp. 45-54.

GASPAR; Jorge (2004) - Técnica, território e poder, In BRANDÃO, Maria (Org.), Milton Santos e o Brasil, Editora Fundação Perseu Abramo, São Paulo

LOURENÇO, Nelson (1993) - Família rural e indústria. Mudança social na região de Leiria. Colecção Estudos, Editorial Fragmentos, Lisboa.

MORENO, Luís (2007) - Desenvolvimento Territorial - de um sentido ocidental às orientações coesivas para um meio rural inovador: Caminhos e Caminhantes, e-book, com base na revisão da sua obra de 2002 intitulada Desenvolvimento Local em Meio Rural: Caminhos e Caminhantes, dissertação de doutoramento em Geografia Humana, Universidade de Lisboa, FLUL, 498 p. + apêndices.

PINHO, João Rocha (2003) - A árvore como monumento. DGF. MA. Lisboa (www.dgrf.minagricultura.pt/v4/dgf/ficheiros/20030323170810DSVPF-P.pdf; consultado em 31 de Dezembro de 2007)

REGULAMENTO (CE) N.o 1698/2005 DO CONSELHO, de 20 de Setembro de 2005, relativo ao apoio ao desenvolvimento rural pelo Fundo Europeu Agrícola de Desenvolvimento Rural (FEADER) Jornal Oficial da União Europeia21.10.2005

RODRIGUES, Margarita e CALLOU, Angelo (www.eca.usp.br) - Estratégias de comunicação rural para o desenvolvimento local: o caso do Conselho Municipal de turismo na Cidade do Conde, Bahia.

SANTOS, Norberto (2007) - Sustentabilidade Urbana. Território e Aplicabilidade. Iberografias, Centro de Estudos Ibéricos, Guarda (no prelo).

SEXTO, Carlos Ferras (2006) - "Mercadotecnia territorial. El territorio como un producto mercantil en la sociedad de la información". Aurora, Braga, 0, pp. 27-40. 